\title{
Engineering Student's Self-Efficacy Judgment to Solve Mathematical Problems in the Classroom or Online
}

\author{
Maria Guadalupe Villarreal- \\ Treviño \\ Nuevo Leon Autonomous University, \\ MEXICO
}

\author{
Ricardo Jesus Villarreal-Lozano \\ Nuevo Leon Autonomous University, \\ MEXICO
}

\author{
Guadalupe Elizabeth Morales- \\ Martinez * \\ National Autonomous University of \\ Mexico, MEXICO
}

\author{
Ernesto Octavio Lopez-Ramirez \\ Nuevo Leon Autonomous University, MEXICO
}

\author{
Norma Esthela Flores-Moreno \\ Nuevo Leon Autonomous University, MEXICO
}

Received: October 6, 2017 - Revised: October 8, $2017 \cdot$ Accepted: October 15, 2017

\begin{abstract}
This study explored in a sample of 560 high level education students their judgment formation to perceived self-efficacy to solve mathematical tasks. Students had to read 36 experimental vignettes describing educative scenarios to learn mathematics. Each scenario presented four manipulated pieces of information (learning modality, task difficulty, task relevance, and structure). After reading each scenario students were required to provide judgments regarding their believed self-efficacy to solve mathematical tasks described in the vignette by using a scale. Results showed that in regard to how students perceived their self-efficacy they could be grouped in two clusters (high and moderate). Most relevant factors to their judgment formation were task difficulty, task relevance and structure. Here, both groups used the same cognitive algebra mechanism to integrate factor information. Here, students valuated academic performance and feedback (e.g. difficulty and relevance) as most relevant even when they are conscious that learning is a primordial target. These and other results are discussed in the paper.
\end{abstract}

Keywords: Self-efficacy perception, mathematics, students, online learning, face to face learning, cognitive algebra.

To cite this article: Villarreal-Treviño, M. G., Villarreal-Lozano, R. J., Morales-Martinez, G. E., Lopez-Ramirez, E. O., \& Flores-Moreno, N. E. (2017). Engineering student's self-efficacy judgment to solve mathematical problems in the classroom or online. European Journal of Educational Research, 6(4), 465-473. doi: 10.12973/eu-jer.6.4.465

\section{Introduction}

Students on a daily basis face academic challenges (e.g. to solve problems, take knowledge tests, to carry on topic presentations in the classroom, etc.) requiring them to set goals, make efforts and commitments to successfully achieve their academic goals (Briones, Morales, Santos, Lopez, \& Urdiales, 2016). It has been documented that in addition to contextual educative factors, type of learning tasks, etc., this goal oriented behavior is mediated by cognitive, motivational and emotional variables (e.g., Hartnett, 2016, Zembylas, Schutz, 2016) as well as by individual factors, such as personal self-efficacy perception to academic success (Bandura, 1995). In particular, it seems that students' beliefs on their own capacity to academic achievement do affect learning outcomes regarding the acquisition of a new knowledge domains (e.g., see Moriarty, Douglas, Punch \& Hattie, 1995), regulate students' perseverance and efforts to achieve a proposed academic goal (Zeldin \& Pajares, 2000) as well as their motivation to success (Bandura, 1995).

Thus, due to the relevance of self-efficacy beliefs of students over their learning outcomes, the self-efficacy variable effect on academic performance have been explored through different academic fields, such as in Chemistry (Dalgety \& Coll, 2006), music (Hendricks, 2015, Hendricks, 2014), the learning of mathematics (Ozyurek, 2005; Lent, Brown, Gover, \& Nijjer, 1996), etc.

Relevant to the current paper are students' efficacy beliefs regarding the learning of mathematics. Research on this topic inside educative settings have dealt with a diversity of educative grades comprehending kindergarten (Tirosh, Tsamir, Levenson, Tabach, \& Barkai, 2013), elementary school (Hung, Huang, \& Hwang, 2014; Schweinle, \& Mims, 2009), junior high and high school (Ozgen, 2013; Lopez \& Lent, 1992; Lent, Lopez, Brown, \& Gore, 1996) and university

\footnotetext{
* Corresponding author:

Guadalupe Elizabeth Morales-Martinez , Cognitive Science Laboratory, Institute of Research on the University and Education, National Autonomous University of Mexico (UNAM, IISUE), Mexico.

Email: gemoramar@hotmail.com
} 
education (Turgut, 2013; Lent, Lopez, \& Bieschke, 1991; Matsui, Matsui \& Ohnishi, 1990, etc.), by using qualitative and quantitative research instruments (Usher \& Pajares, 2008, Usher, 2009), like Likert scales and questionnaires (Cheema \& Kitsantas, 2014; Peters, 2013; Bagaka's, 2011), experimental design studies (Hung, Huang \& Hwang, 2014) interviews (Tirosh, Tsamir, Levenson, Tabach, \& Barkai, 2013), etc.

The Organization for Economic Cooperation and Development (OECD, 2013) has promoted academic exploration on how mental variables like self-concept, self-efficacy as well as commitment toward mathematical activities are considered inside and outside educative environments in countries like Portugal, Poland, Canada, New Zeeland, Mexico, Colombia, etc. Results regarding this academic enterprise support that mathematical competencies and self-efficacy are strongly related. Specifically, students having high self-efficacy perception of themselves have better mathematical competencies than low self-efficacy perception students. Collateral research has shown that students with high selfefficacy perception of themselves distribute their time more efficiently, show more perseverance to solve tasks and use wider set of self-regulation strategies to achieve academic success (Schunk \& Pajares, 2002).

In regard to self-efficacy and gender differences, it has been observed that previous experience in a topic affects male students' efficacy perception (Lent, Lopez et al., 1996) whereas social persuasion is most relevant to female students' perception of efficacy (Lopez et al., 1997; Lopez \& Lent, 1992). This suggests that male students' self-efficacy perception is oriented to themselves and female perceptions are oriented to others opinions (Lopez et al., 1997; Lopez \& Lent, 1992).

However, complementary research noted that the way previous experience affect students' self-efficacy perceptions depend on their ethnic origin. For instance, white students perceived efficacy seem to be most favored from any previous experience (Smith, 2001), but Hispanic students' perceptions are most benefited from previous experiences if these are vicarious (Stevens et al., 2006). Additional factors affecting the impact of previous experience over students' self-efficacy perceptions relate to experience magnitude, academic domain, academic competency, social persuasion and even physiological stages of students (Usher \& Pajares, 2008).

Overall, a major benefit obtained from the previous appointed research has been the identification of relevant factors affecting students' psychological self-efficacy perception regarding learning or practicing mathematics as well as determination of how these factors vary to mediate these perceptions. Briones-Rodriguez et al. (2016), have taken this factor specification to develop cognitive specification of factor interaction by using an Information Integration Theory approach (IIT, Anderson, 2007). By using an IIT approach as well as its cognitive algebra research techniques these authors specified cognitive mechanism underlying self-efficacy judgment formation regarding the learning of mathematics. This approach to cognitive specification has been proven useful to explore the cognitive information processing mechanisms that people use in different aspects of their lives (education, health, economy, etc.).

For instance, Briones et al. (2016) noticed that students in their study used a cognitive summative rule to integrate factor information to judgment formation regarding the learning of mathematics independently if the learning environment was a classroom or online. The study proposal was that this way to cognitive specification of judgment formation regarding mathematical self-efficacy could be used to explore the same student's perceptions at different education levels. This is the main concern in the present study since its intention is to seek for evidence suggesting that same cognitive summative rule used by high school students is the same cognitive mechanism used by university bachelor students to self-efficacy judgment formation regarding the learning of mathematics.

\section{The present study}

In this study we seek to explore information integration cognitive mechanisms used by engineering students to selfefficacy judgment formation regarding the learning of mathematics. As such, the current research can be seen as a follow up IIT study from Briones et al. study on learning mathematics (2016). However, the current research focus in a high level education sample and at the same it considers students' cognitive styles. The intention is to maintain a proposed empirical duration to specify cognitive parameters that students use to valuate and integrate information of education contexts and personal competencies to learn and practice mathematics.

\section{Design}

\section{Methodology}

The experimental design used in this study consisted of orthogonal combination of factor levels regarding assigned types of task to learn mathematics and the education modality used to deliver these tasks (Briones-Rodriguez et al., 2016). That is, a 2(modality: virtual vs. face to face instruction) x 2(task difficulty: high vs. low) x 3 (level of teaching structure: High vs. medium vs. low) x 3 (task relevance: High vs. medium vs. low). Thus, combination of factor levels produces 36 experimental conditions which are used to implement the study instrument. 


\section{Instrument}

The cognitive algebra instrument consisted of 36 scenarios based on experimental factor levels combinations. Each scenario briefly described a specific educative context to take a mathematic class. After each scenario, at the bottom part of the written scenario a question was presented. Here, the question asked the participant to evaluate her/his selfefficacy perception to take a class by using a ten points scale ranged between the 0 and 10 (see description of one scenario in Appendix 1).

Furthermore, to explore how variables like locus of control and goal oriented behavior relate to mathematics selfefficacy perception two scales were considered. First, the Internality, Powerful Others and chance Levenson scale or IPC Levenson scale (Levenson, 1981), containing 3 sub-scales (Internality, Powerful Others and chance) ranged between -3 to +3 (six point scales).

Here, to obtain scale scores participant' responses are added plus a constant of 24 to eliminate negative values. The range of score values that can be obtained is between 0 to 48. Levenson (1974) reported that obtained scale reliability for a sample of 152 students by using a Kuder Richardson method was .64 for the "I" scale, .77 for the "P" scale, and .78 for the scale "C".

Secondly, two scales regarding goal oriented behavior were considered in this study (Performance goal orientation or PGO and Learning goal orientation or LGO of Button, Mathieu, \& Zajac, 1996). The goal was to obtain information about students' inclination toward academic learning or academic performance. Each scale, contained 10 items valuated between 1 and 7. These were left anchored with a message "strongly disagree" (1) and right anchored with a message "strongly agree". Button et al. (1996) used this scale in sample of 374 bachelor psychology students and he obtained a Cronbach value of .76 to PGO and a Cronbach reliability value of .79 for the LGO scale.

Finally, the Marlowe-Crowne Social Desirability Scale (Crowne \& Marlowe, 1960) was used as one study control. This scale consisted of 33 items having each dichotomic possible answers (true vs. false). Scale authors have obtained a reliability score of .88 on their scale by using the Kuder-Richardson formula 20.

\section{Sample and Data Collection}

This cognitive algebra study considered a sample of 560 bachelor students from different engineering fields. They were residents from a population at the North of Mexico and their age ranged between 17 and 29 years old $(\mathrm{M}=19.22, \mathrm{SD}=$. 1.57). Here, $27 \%$ (151) participants were female students and 73\% (409) were male students. All of them were single and did not received any financial remuneration but some points on their grade course were awarded.

\section{Procedure}

A first step consisted a Facebook call to students for participation in the study. Secondly, after enrollment, each student was contacted to let them know study details, their confidentiality rights and written consent was obtained. Then participants proceeded to take the study. Here, they were required to provide demographic information by taking a questioner. After instructions had to take a practice session. Finally, each student had to read the randomly presented vignettes. After reading each described scenario participants had to provide a judgment about their perceived selfefficacy to carry on a mathematical task. The required time to go through all experimental session was between 20 and 30 minutes.

\section{Analyzing of Data}

A cluster analysis was carried on over the obtained 560 participants' raw data judgment scores (using K-means, Euclidean distances). The intention was to look for possible different perceived self-efficacy judgment groups. After cluster identification an ANOVA was carried on over each group judgment scores to determine their cognitive algebraic information integration rule to judgment formation.

\section{Findings / Results}

\section{Cluster analysis}

The cluster analysis showed the existence of two significant different response patterns among study participants $\left(\eta^{2}=\right.$ $.65)$. The first cluster $(\mathrm{N}=346,61.78 \%)$ consisted of a group of students having a high APM (M= 8.1 DE=.9) in both teaching modalities: Virtual $(\mathrm{M}=8)$, or in person $(\mathrm{M}=8)$. Because of this, the cluster group was labeled as the high selfefficacy judgment group. This cluster grouped 87 female scores (25.14\%) and 259 male judgment scores (74.855\%). A second cluster of students $(\mathrm{N}=214,38.21 \%)$ had a moderate APM index in both teaching modalities: Virtual (M= 8), or in person $(M=8)$. Because of this, the cluster group was labeled as moderate self-efficacy judgment group. This group included 64 female students (20\%) and 150 male students (70\%). Some results regarding social desirability, locus of control and goal oriented behavior for each cluster are shown in table1. 
Table 1. Comparison table showing social desirability, locus of control and goal oriented behavior indexes for each cluster.

\begin{tabular}{llllc}
\hline & & \multicolumn{2}{c}{$\begin{array}{c}\text { Scores to each } \\
\text { clúster }\end{array}$} & Comparison \\
\hline \multicolumn{1}{c}{ Scale } & \multicolumn{1}{c}{ Subscales } & $\mathbf{1}$ & 2 & T- student \\
& & & & \\
\hline Social Desirability & Social Desirability & 19.82 & 17.58 & $t(558)=-5,02^{*}$ \\
Locus of control & Internality & 35.24 & 33.51 & $t(558)=-3,82^{*}$ \\
& Powerful Others & 14.38 & 17.13 & $t(558)=4,32^{*}$ \\
& Chance & 16.60 & 18.02 & $t(558)=2,22^{*}$ \\
Goal orientation & Performance goal orientation & 51.93 & 51.43 & $n s$ \\
& Learning goal orientation & 62.36 & 57.87 & $t(558)=-8,32^{*}$ \\
\hline
\end{tabular}

*Significancia al nivel de $\mathrm{p}<.05$.

ANOVA

A within ANOVA was carried over each cluster data. Here a 2 (Modality: Face to face learning vs. Online learning) x 2 (Task difficulty; High vs. Low) x 3 (Degree of instruction structure: Low vs. Middle vs. High) x 3 (Task relevance: High vs. Medium vs. Low) experimental design was considered for this purpose. Significance criterion was set to $\mathrm{p}<.001$.

Table 2. ANOVA results for each cluster.

\begin{tabular}{|c|c|c|c|c|c|c|c|}
\hline Source & $d f$ & $M S$ & $d f$ & $M S$ & $\mathbf{F}$ & $p$ & $\eta^{2}$ \\
\hline \multicolumn{8}{|c|}{$\begin{array}{l}\text { Cluster } 1 \\
\text { f-efficacy judgment }>>\end{array}$} \\
\hline Modality (M) & 1 & 6.07 & 345 & 1.51 & 3.995 & .04 & .01 \\
\hline Difficulty (D) & 1 & 3986.85 & 345 & 9.17 & 434.53 & .001 & .55 \\
\hline Structure (S) & 2 & 74.40 & 690 & 1.80 & 41.15 & .001 & .10 \\
\hline Relevance (R) & 2 & 108.48 & 690 & 2.47 & 43.83 & .001 & .11 \\
\hline$M^{*} D$ & 1 & 0.009 & 345 & 1.07 & 0.009 & .92 & .00 \\
\hline$M^{*} S$ & 2 & 0.70 & 690 & 0.99 & 0,70 & .49 & ,002 \\
\hline $\mathrm{M}^{*} \mathrm{R}$ & 2 & 0.65 & 690 & 0.87 & 0.75 & .47 & .002 \\
\hline$D^{*} S$ & 2 & 0.96 & 690 & 0.89 & 1.07 & .34 & .003 \\
\hline $\mathrm{D}^{*} \mathrm{R}$ & 2 & 10.96 & 690 & 1.25 & 8.76 & .001 & .02 \\
\hline $\mathrm{S} * \mathrm{R}$ & 4 & 1.65 & 1380 & 0.97 & 1.68 & .14 & .004 \\
\hline \multicolumn{8}{|c|}{$\begin{array}{c}\text { Cluster } 2 \\
<<\text { Moderate self-efficacy judgment }>>\end{array}$} \\
\hline Modality (M) & 1 & .29 & 213 & 3.26 & 0.09 & .762 & .0004 \\
\hline Difficulty (D) & 1 & 10996.05 & 213 & 29.88 & 367 & .001 & .63 \\
\hline Structure (S) & 2 & 34.84 & 426 & 3.39 & 10.25 & .001 & .04 \\
\hline Relevance (R) & 2 & 197.74 & 426 & 7.66 & 25.80 & .001 & .10 \\
\hline $\mathrm{M}^{*} \mathrm{D}$ & 1 & 13.62 & 213 & 1.86 & 7.30 & .007 & .03 \\
\hline$M * S$ & 2 & .70 & 426 & 2.03 & 0.34 & .70 & .001 \\
\hline$M^{*} \mathrm{R}$ & 2 & 2.94 & 426 & 1.92 & 1.53 & .21 & .007 \\
\hline$D^{*} S$ & 2 & .92 & 426 & 2.09 & 0.44 & .64 & .002 \\
\hline $\mathrm{D}^{*} \mathrm{R}$ & 2 & 22.25 & 426 & 2.53 & 8.77 & .001 & .03 \\
\hline $\mathrm{S} * \mathrm{R}$ & 4 & .89 & 852 & 2.01 & 0.44 & .77 & .002 \\
\hline
\end{tabular}

*Significance criterion $\mathrm{p}<.001$.

Note from the last previous table that most relevant factors to both clusters were task difficulty, task relevance and task structure. Task modality was not relevant to any group. However, it is important to notice cluster 1 imposer higher relevance to modality than cluster 2 even when this difference was not significant.

Furthermore, notice that to both groups the higher weighted factors are multiplicative (Difficulty vs. Relevance). Even when the factor interaction effect is minimum (see Figure 1). Thus in Figure 1 it can be observed that the higher the task difficulty, then the task relevance highly affect the self-efficacy perception judgment. Moreover, it can be observed that both groups used the same information integration mechanisms. 
Cluster 1

High self-efficacy judgment
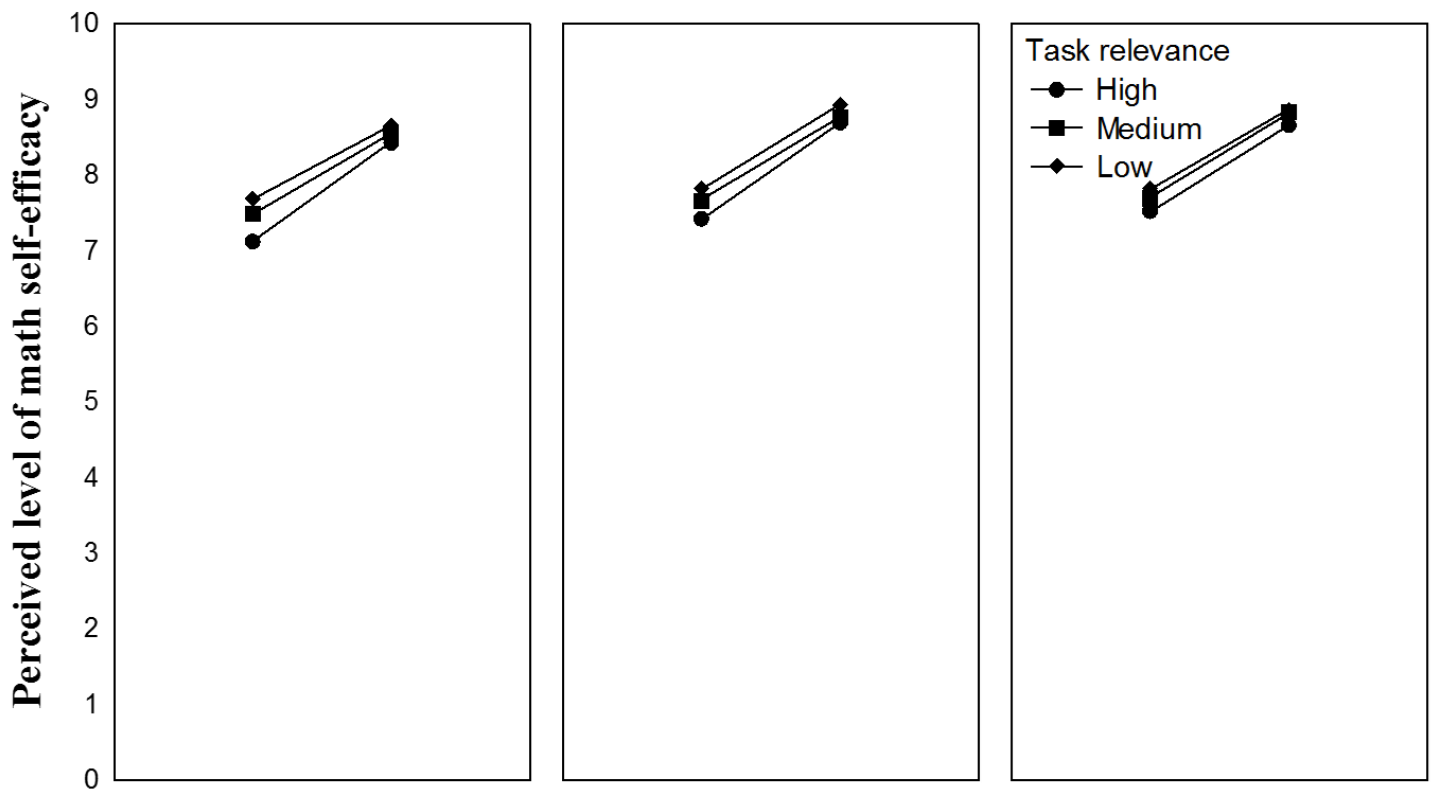

Cluster 2

Moderate self-efficacy judgment
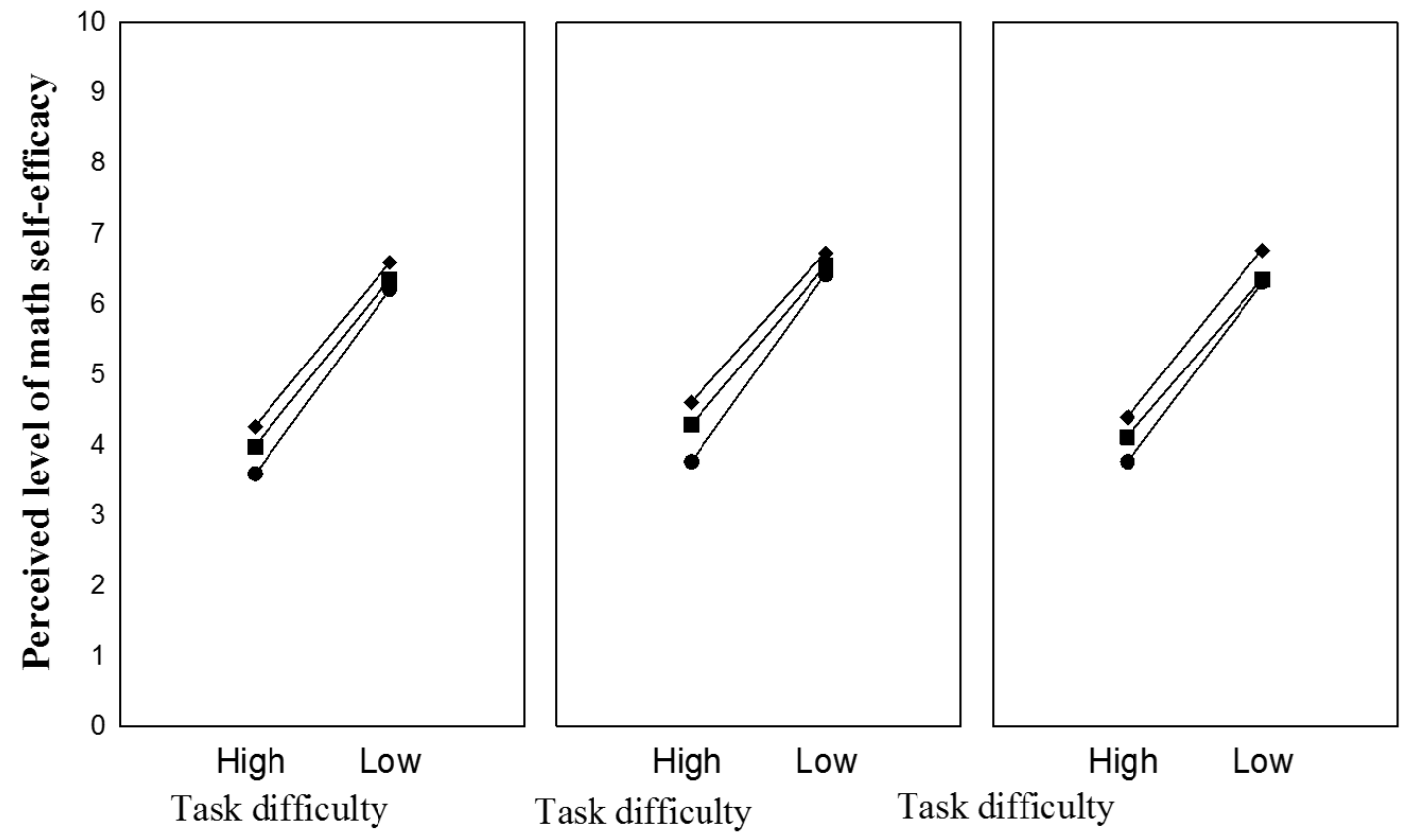

Low

Task difficulty

Task difficulty

Medium

High

Degree of instruction structure

Figure 1. A factor integration graph (Difficulty vs relevance vs structure) showing the information integration cognitive mechanism used by students through the experimental conditions. The top panel shows the high self-efficacy judgment group performance whereas the bottom panel describes the students' moderate self-efficacy performance.

Taken together, the study results suggest that perceived self-efficacy to learn and practice of mathematics among bachelor students was moderate $(M=5.2, S D=1.2)$. No significant main effect was obtained regarding the gender factor and self-efficacy $F(1,558)=2.91, p=.08, \eta 2=.005$. Even though it is interesting to mention that female students obtained lower self-efficacy scores $(M=6.8)$ then male students $(M=7.1)$. 


\section{Discussion and Conclusion}

This study aimed to identify information integration cognitive mechanisms underlying self-efficacy judgment to learn mathematics. Here, students showed a moderate to high self-efficacy perception based on valuation and information integration of factors like difficulty, relevance and structure of learning tasks (see Table 1 and Figure1).

In both clusters, the cognitive integration mechanism appears to be moderated by a multiplicative cognitive rule. The task difficulty seems to increase the effect of the task relevance when both interact, although, as can be seen in the graph, the interaction effect is very small.

Here, it is relevant to mention that the appointed clusters relate more to the perceived self-efficacy than to the identified factor information integration cognitive rule. This is interesting because previous research carried on middle level education environments (Briones et al., 2016) found that even when students consider ed in this research used the same information integration rule (summative), factor valuation in both groups was significantly different. The reason of why factor information integration and factor weight valuation is different between middle students and high level education students is not clear. Thus, research is on demand to explore if variables like students age, carrier, their interest in mathematics or students' personal characteristic (e.g. locus of control, preference to the subject content), etc. can provide insights to explain these differences. For instance, note that in this study the high self-efficacy judgment group had a higher locus of control score and higher orientation to learn a task score than students in the low selfefficacy cluster.

This low self-efficacy group showed an external agency process (imposing locus of control to others and locus of control to random events). By considering this, it would be interesting to explore if external agency processes have an effect either over perceived self-efficacy to learn mathematics or over the cognitive rule to valuate and integrate information to learn mathematics. Here, notice that even when study participants imposed relevance to performance (e.g. task relevance), they did not put out of the equation searching for learning strategies to achieve academic success (looking for task structure adaptation). This also happened in one of the Briones et al. (2016) study group.

In the current study most of the participants had a special interest on feedback, imposing a second place to the factor regarding orientation to learning. This is so even when students have consciousness that learning by itself is very relevant as it can be noticed from the orientation toward learning scale. Therefore, a question arises about why students impose a major weight to task relevance even when this variable is more associated to performance rather than learning? A possibility is that the cognitive algebra instrument locates a participant in a more possible contextualized real social situation where performance prevails over other factors to academic success. This kind of social contextualized cognitive specification is the research goal under an IIT approach. Thus the IIT ecological approach relies on how to contextualize judgment formation inside educative environments similar to reality. Here, cognitive algebra scenarios empower researchers to explore everyday educative scenarios.

\section{References}

Anderson, N. H. (1982). Methods of information integration theory. New York: Academic Press.

Bagaka's, J. G. (2011). The role of teacher characteristics and practices on upper secondary school students' mathematics self-efficacy in Nyanza province of Kenya: a multilevel analysis. International Journal of Science and Mathematics Education, 9(4), 817-842. doi:10.1007/s10763-010-9226-3

Bandura, A. (1995). Exercise of personal and collective efficacy in changing societies. In A. Bandura (Eds.), Self-efficacy in changing societies. (pp. 1-45). UK: Cambridge University Press. doi: 10.1017/CB09780511527692

Briones-Rodriguez, C., Moralez-Martinez, G.E., Santos- Alcantara, M.G., Lopez-Ramirez, E.O., \& Urdiales-Ibarra, M.E (2016). Cognitive algebra underlying high school student's self-efficacy judgment to solve mathematical problems in the classroom or online. International Journal of Education, 8(2), 136-148. doi: 10.5296/ije.v8i2.9148. URL: http://dx.doi.org/10.5296/ije.v8i2.9148

Button, S. B., Mathieu, J. E., Zajac, D. M. (1996). Goal orientation in organizational research: A conceptual and empirical foundation. Organizational behavior and human decision processes, 67(1), 26-48.

Cheema, J. R., \& Kitsantas, A. (2014). Influences of disciplinary classroom climate on high school student self-efficacy and mathematics achievement: a look at gender and racial-ethnic differences. International Journal of Science and Mathematics Education, 12(5), 1261-1279. doi:10.1007/s10763-013-9454-4

Crowne, D. P., \& Marlowe, D. (1960). A new scale of social desirability independent of psychopathology. Journal of Consulting Psychology, 24, 349354.

Dalgety, J., \& Coll, R. K. (2006). Exploring first-year science students' chemistry self-efficacy. International Journal of Science and Mathematics Education, 4(1), 97-116. doi:10.1007/s10763-005-1080-3

Hartnett, M. (2016). Motivation in online education. Singapore: Springer 
Hendricks, K. S. (2014). Changes in self-efficacy beliefs over time: Contextual influences of gender, rank-based placement, and social support in a competitive orchestra environment. Psychology of Music, 42(3), 347-365. doi:10.1177/0305735612471238

Hendricks, K. S. (2015). The sources of self-efficacy: Educational research and implications for music. Update: Appliations of Research in Music Education, 35(1), 1-7. doi:10.1177/8755123315576535

Hung, C. M. (2014). Effects of digital game-based learning on students' self-efficacy, motivation, anxiety, and achievements in learning mathematics. Journal of Computers in Education, 1(2-3), 151-166. doi:10.1007/s40692014-0008-8

Lent, R. W., Brown, S. D., Gover, M. R., \& Nijjer, S. K. (1996). Cognitive assessment of the sources of mathematics selfefficacy: A thought-listing analysis. Journal of Career Assessment, 4(1), 33-46. doi: 10.1177/106907279600400102

Lent, R. W., Lopez, F. G., \& Bieschke, K. J. (1991). Mathematics self-efficacy: Sources and relation to science-based career choice. Journal of Counseling Psychology, 38(4), 424-430.

Lent, R. W., Lopez, F. G., Brown, S. T., \& Gore Jr., P. A. (1996). Latent structure of the sources of mathematics self-efficacy. Journal of Vocational Behavior, 49(3), 292-308. doi:10.1006/jvbe.1996.0045

Levenson, H. (1974). Activism and powerful others: Distinctions within the concept of internal-external control. Journal of Personality Assessment, 38, 377-383.

Levenson, H. (1981). Differentiating among internality, powerful others, and chance. In H. M. Lefcourt (Ed.), Research with the locus of control construct (Vol. 1, pp. 15-63). New York: Academic Press.

Lopez, F. G., \& Lent, R. W. (1992). Sources of mathematics self-efficacy in high school students. The career development quarterly, 41(1), 3-12. doi: 10.1002/j.2161-0045.1992.tb00350.x

Matsui, T., Matsui, K., \& Ohnishi, R. (1990). Mechanisms underlying math self-efficacy learning of college students. Journal of Vocational Behavior, 37(2), 223-238. doi:10.1016/0001-8791(90)90042-Z

Moriarty, B., Douglas, G., Punch, K., \& Hattie, J. (1995). The importance of self-efficacy as a mediating variable between learning environments and achievement. British Journal of Educational Psychology, 65(1), 73-84. doi:10.1111/j.2044-8279.1995.tb01132.x

Ozgen, K. (2013). An analysis of high school students' mathematical literacy self-efficacy beliefs in relation to their learning styles. The Asia-Pacific Education Researcher, 22(1), 91-100. doi:10.1007/s40299-012-0030-4

Ozyurek, R. (2005). Informative sources of math-related self-efficacy expectations and their relationship with mathrelated self-efficacy, interest, and preference. International Journal of Psychology, 40(3), 145-156. doi:10.1080/00207590444000249

Peters, M. L. (2013). Examining the relationships among classroom climate, self-efficacy, and achievement in undergraduate mathematics: A multi-level analysis. International Journal of Science and Mathematics Education, 11(2), 459-480. doi: 10.1007/s10763-012-9347-y

Schunk, D. H., \& Pajares, F. (2002). The development of academic self-efficacy. In A. Wigfield, \& J. Eccles (Eds.), Development of achievement motivation (pp. 15-31). San Diego, CA: Academic Press. doi: http://dx.doi.org/10.1016/B978-012750053-9/50003-6

Schweinle, A., \& Mims, G. A. (2009). Mathematics self-efficacy: stereotype threat versus resilience. Social Psychology of Education, 12, 501-514. doi:10.1007/s11218-009-9094-2.

Smith, S. M. (2001). The four sources of influence on computer self-efficacy. Delta Pi Epsilon Journal, 43(1), 27-39.

Stevens, T., Olivárez, A., \& Hamman, D. (2006). The role of cognition, motivation, and emotion in explaining the mathematics achievement gap between Hispanic and White students. Hispanic Journal of Behavior Sciences, 28(2), 161-186. doi: 10.1177/0739986305286103

Tirosh, D., Tsamir, P., Levenson, E., \& Tabach, M. (2013). Exploring young children's self-efficacy beliefs related to mathematical and nonmathematical tasks performed in kindergarten: abused and neglected children and their peers. Educational Studies in Mathematics, 83(2), 309-322. doi:10.1007/s10649-012-9458-y

Turgut, M. (2013). Academic self-efficacy beliefs of undergraduate Mathematics education students. Acta Didactica Napocensia, 6(1), 33-39.

Usher, E. L., \& Pajares, F. (2008). Sources of self-efficacy in school: Critical review of the literature and future directions. Review of Educational Research, 78(4), 751-796. doi:10.3102/0034654308321456 
Usher, E. L. (2009). Sources of middle school students' self-efficacy in mathematics: A qualitative investigation. American Educational Research Journal, 46(1), 275 -314. doi:10.3102/0002831208324517.

Zeldin, A. L., \& Pajares, F. (2000). Against the odds: Self-efficacy beliefs of women in mathematical, scientific, and technological careers. American Educational Research Journal. 37(1), 215-246. doi: 10.3102/00028312037001215

Zembylas, M., \& Schutz, P. A. (2016). Methodological advances in research on emotion and education. Switzerland: Springer. 


\section{Appendix}

\section{Scenario 1}

During a math class, your teacher has assigned you an online activity. He will clarify your doubts about the drafting of the problems or the instructions for completing the assignment through a virtual platform (no aspect of the activity is discussed in the classroom; it is completely online).

The activity requires you to solve a series of very difficult problems within a time limit. You may not use any device or additional help to carry out the activity.

The teacher does not provide many instructions; he does not describe how that math operations need to be performed (mentally or on paper). He did not specify if it is necessary to verify the procedures used or if there are rules to follow to present the activity.

This is a required activity in order to take the final test and it affects the final course score. Thus, success in this course highly depends on realizing the appointed task.

In this situation, how would you judge your ability to perform the activity? Not capable to perform it $0--0--0--0--0--0--0--0--0--0--0$ totally capable of performing it 